\title{
A importância e o legado de Alberto Magno na CONTROVÉRSIA SOBRE A UNICIDADE DO INTELECTO
}

\author{
Matteo Raschietti ${ }^{1}$
}

\begin{abstract}
Resumo: A finalidade deste trabalho é destacar importância e o legado do dominicano Alberto Magno na controvérsia com os defensores da unicidade do intelecto possível para todo o gênero humano. Para tanto, será feita uma apresentação sumária do seu tratado De unitate intellectus, redigido em 1263. Após uma contextualizaçáo histórica que apresenta a posição do bispo de Regensburg diante das teses averroístas, procurar-se-á mostrar como ele foi o inspirador, quanto a essa questáo, de um dos seus alunos mais brilhantes: Tomás de Aquino. Além disso, deseja-se frisar como, para o Doctor Universalis, a contribuição de Averróis se revelasse indispensável: este soube indicar, com efeito, a maneira correta segundo a qual o intelecto devia ser considerado "imaterial”, embora sua conclusão da existência de um único intelecto possível para todo gênero humano fosse inaceitável.
\end{abstract}

Palavras-Chave: Alberto Magno. Intelecto. Averroísmo. De anima.

\section{INTRODUÇÃo}

No século XIII, a investigação filosófica sobre a natureza do intelecto ocasionou debates acalorados que, junto com a recepção de novas categorias conceituais, ensejaram contraposiçôes que se prolongaram em épocas sucessivas. O dominicano Albrecht Von Bollstädt, conhecido ainda em vida como Doctor Universalis e Doctor Expertus (chegando a ganhar o epíteto Magnus quando idoso), teve um papel fundamental na discussão acerca da unicidade ou pluralidade do intelecto possível para toda espécie humana, ao lado de outros pensadores como o confrade Tomás de Aquino e Síger de Brabante, mestre da Faculdade de Artes de Paris entre 1266 e 1276.

A difusão do corpus aristotelicum no mundo latino, em relação à qual Alberto Magno assumiu uma atitude de receptividade aberta e corajosa que

1 Professor da Universidade Federal do ABC (UFABC), São Bernardo do Campo, SP - Brasil. (D) https://orcid.org/0000-0002-1527-5432 E-mail: matteo.raschietti@ufabc.edu.br

http://dx.doi.org/10.1590/0101-3173.2019.v42esp.05.p75 
se traduziu no seu projeto de expor e parafrasear toda a obra do Estagirita (ALBERTO MAGNO, 2017, p. 8), colocou à disposição novas categorias conceituais, enfatizando a possibilidade de oferecer uma leitura racional do mundo, a um só tempo filosófica e científica, independente da revelação. Em particular, o De anima de Aristóteles oferecia novas estratégias para definir e compreender a alma humana a partir das operaçóes inerentes ao ser humano. No entanto, dificuldades hermenêuticas presentes no texto aristotélico, cujas tentativas de solução interessaram a tradição peripatética grega e árabe (que, a partir de Teofrasto, Temístio, Alexandre de Afrodísia chegara aos latinos através de Avicena, Avicebron, Maimônides e Averróis), propiciaram o surgimento de problemas até então inéditos: a eternidade do mundo (BIANCHI, 1984), a unicidade do intelecto possível, a questão da dupla verdade, entre outros.

No esforço de compreender a doutrina aristotélica do intelecto que o Estagirita, às vezes em modo críptico, deixara registrado no De anima, comentadores antigos e medievais (árabes, judeus e latinos), buscaram responder a várias questôes, entre as quais: o intelecto é individual? $\mathrm{O}$ que significa que "é separado, impassível e sem mistura?" (ARISTÓTELES, 2006, p. 116) Qual sua relação com o comportamento humano? Em que sentido ele pode sobreviver ao corpo? Os mestres medievais, após o ingresso das obras aristotélicas no ensino universitário (cuja leitura, a partir de 1252, tornara-se obrigatória), foram chamados a responder a essas questóes, e suas posições nem sempre foram concordes, aliás: franciscanos e dominicanos, particularmente, travaram discussóes acaloradas, cada um defendendo sua posição filosófica.

O objetivo deste artigo é delinear a posição assumida por Alberto Magno na controvérsia antiaverroísta através de uma apresentação sumária do tratado De unitate intellectus (Sobre a unidade do intelecto). Após uma contextualização do problema, procurar-se-á compreender como a diatribe sobre a unicidade do intelecto possível foi originada por uma instância especulativa muito nítida: a tese da imaterialidade do intelecto. A esse respeito é preciso frisar que, para o dominicano alemão, a contribuição de Averróis era indispensável: com efeito, este soube indicar a maneira correta segundo a qual o intelecto devia ser considerado "imaterial"; entretanto, sua conclusão da existência de um único intelecto possível para todo gênero humano, era inaceitável. 


\section{Alberto Magno e a propagação das teses aVerroístas}

Quando da sua volta à Alemanha vindo de Paris, à época da fundação do Studium generale de Colônia (1248), o dominicano de Bollstädt deu uma guinada radical à sua orientaçáo intelectual: por um lado, começou seu grande plano de exposição sistemática do corpus aristotelicum a partir dos Physicorum libri, satisfazendo um desejo que seus confrades lhe tinham manifestado; de outro, com as liçóes sobre a ética aristotélica (1250), principiou uma reflexão crítica a respeito da relação entre filosofia e teologia. A influência de Averróis, em ambos os casos, foi determinante. Naqueles anos, a cultura europeia da Idade Média se confrontava, pela primeira vez, com um sistema físico e metafísico totalmente novo para a tradição cristã, e era necessário escolher ideias e doutrinas que não contrastassem com o conjunto da fé cristã. Em relação a Aristóteles era preciso, segundo as palavras do próprio Alberto, "torná-lo inteligível aos latinos"2.

$\mathrm{Na}$ universidade de Paris, nesse meio tempo, deflagrara-se um conflito entre o clero secular e as ordens mendicantes pelo direito de ensinar na universidade. Esta era considerada a mais prestigiosa da época para o estudo da teologia, e os estudantes provinham de muitas regióes da Europa. O latim era a língua oficial do ensino universitário, enquanto as comunidades dos estudantes estavam organizadas em quatro nationes, de acordo com a língua de origem: francesa (onde estudavam também os italianos), picarda, normanda e inglesa (onde estudavam também os alemáes). Entre 1253 e 1254, os mendicantes se recusaram a aderir a uma greve do clero secular e um grupo de teólogos, chefiados por Guillaume de Saint-Amour,

escreveu um documento à Cúria Papal, solicitando que fossem negados às Ordens a competência universitária e o direito de existir. Alberto Magno apresentou-se como advogado das Ordens Mendicantes e, com sua brilhante argumentação, refutou todas as invectivas de Guillerme de St. Amour. (RODRIGUES, 2015, p. 36).

Em 1256, o mestre dominicano foi enviado para Anagni (onde, naquele momento, se encontrava a corte papal) a fim de defender a causa das ordens mendicantes, permanecendo lá até 1257 . Solicitado pelo papa Alexandre IV, sustentou uma disputa sobre a tese da unicidade do intelecto possível para toda espécie humana, defendendo, contra essa tese, a pluralidade dos intelectos e

2 Nostra intentio est omnes dictas partes (physicam, metaphysicam et mathematicam) facere latini intelligibiles. (Phys., 1.I, tr. 1, cap. 1 apud DE WULF, 1936, p. 133, tradução nossa). 
a imortalidade pessoal da alma. A redação definitiva desta disputa, conhecida como De unitate intellectus, foi realizada por volta de 1263; o dominicano, em seguida, retomou o libellus, fez algumas modificaçóes e o inseriu na segunda parte da Summa theologiae, sua obra mais tardia (RODRIGUES, 2015, p. 40).

Este tratado manifestava a intenção do Doctor Universalis de propor uma reforma da psicologia averroísta, da qual, segundo Sturlese, "ele compartilhava o objetivo primário de fundamentar a universalidade do conceito em modo não empírico, pretendendo fazer isso sem renunciar a enraizar no sujeito empírico a função intelectiva" (STURLESE, 1996, p. 108, tradução nossa). O mesmo autor sustenta que não é possível saber quando as traduçóes latinas de Averróis chegaram pela primeira vez na Alemanha, e tampouco por onde elas ingressaram (STURLESE, 1994, p. 116, tradução nossa). À época do "primeiro averroísmo" (um movimento de ideias heterodoxas dentro da Faculdade de Artes suscitado pelo desejo de interpretar o pensamento de Aristóteles sem se importar com os conflitos que suas conclusôes podiam ocasionar contra o dogma cristão), Alberto Magno se encontrava nos conventos dominicanos alemães após ingressar na Ordem dos Pregadores, em 1223, na cidade de Pádua, prosseguindo, depois, sua carreira na cidade de Colônia (RODRIGUES, 2015, p. 35). Sua posição em relação ao filósofo muçulmano estava ligada ao modo de se relacionar com a filosofia aristotélica e com a filosofia pagã: já no comentário ao Liber II Sententiarum, afirma Sturlese, o dominicano de Bollstädt reparara que, no caso da ciência natural, era melhor confiar mais em Aristóteles "ou em outro que seja experto nas coisas da natureza"3 do que em Agostinho; sua exposição das obras aristotélicas, vale ressaltar, era feita sempre ficando de olho nos comentários de Averróis. A reflexão albertiana sobre a relação entre filosofia e teologia evidenciava também uma forte influência averroísta: isso se manifestava no puro exercício da racionalidade, independentemente da revelação, sobretudo no que dizia respeito à psicologia e sua análise da alma intelectiva, a partir do princípio: homo est homo per intellectum (ALBERTI MAGNI, I, c. 5 apud NARDI, 1960, p. 25). Além desse princípio, outros dois pontos da psicologia averroísta assumidos por Alberto influenciaram decididamente a escola alemã medieval: primeiro, a consideraçáo do intelecto enquanto intelecto (que é único) e enquanto faculdade do sujeito empírico (que é individual); segundo, a doutrina do "intelecto adquirido" (intellectus adeptus), após lograr o qual o

\footnotetext{
${ }^{3}$ Et si de naturis rerum loquatur, credo Aristotelis plus vel aliis experto in rerum naturis. (ALBERTI MAGNI, II Sent. apud STURLESE, 1994, p. 117, traduçấo nossa).
} 
homem se tornava "perfeito em relação à sua atividade humana especifica, quer dizer, em relação à contemplação e ao conhecimento, por si mesmo, da realidade imaterial" (ANZULEWICZ, 2011, p. 81-82, tradução nossa). Através do intelecto adquirido, o ser humano podia transcender a contingência e se tornar perfeito em relação à sua atividade especificamente humana: nisso, para Alberto, consistia a beatitudo suprema do ser humano, que não devia esperar a vida ultraterrena para ver sua realização: "O intellectus speculativus é a base antropológica para o estágio da plenitude do entendimento humano, quer dizer, para obter o intellectus adeptus, resultante da união do intellectus agens ut forma com o intellectus possibilis." (ANZULEWICZ, 2011. p. 82, tradução nossa).

\section{O papel de Alberto Magno na época da Condenaçáo de 1270}

No dia 10 de dezembro de 1270, o bispo Estêvão Tempier de Paris condenou e excomungou treze proposiçóes ensinadas na Faculdade de Artes, junto com seus fautores: "Estes são os erros condenados e excomungados com todos aqueles que tê-los-ão ensinado ou sustentado conscientemente, pelo senhor Estêvão, Bispo de Paris, ano do Senhor 1270, quarta-feira após a festa do bem-aventurado Nicola, no inverno" ${ }^{4}$. Quatro eram as doutrinas às quais a condenação de Tempier mirava: 1) a negação da providência divina em relação às coisas contingentes; 2) a eternidade do mundo; 3) a unidade numérica do intelecto humano; 4) a negação do livre-arbítrio (MANDONNET, 1908-1911, p. 112, traduçấo nossa). Naquele ano Tomás de Aquino (que já se confrontara com esses erros quando do primeiro ensino parisiense, de 1252 a 1259), estava no ápice da sua porfia contra "o mais aberrante dos erros (indecentior)":

Assim como todos os homens desejam naturalmente conhecer a verdade, também é inerente aos homens o desejo natural de evitar os erros e de refutá-los, quando tiverem essa capacidade. Ora, dentre outros erros, o mais aberrante parece ser o erro através do qual se erra a respeito do intelecto, pelo qual somos capacitados por nascença a, afastados os erros, conhecer a verdade. (TOMÁS DE AQUINO, 2016, p. 19).

\footnotetext{
${ }^{4}$ Isti sunt errores condemnati et excomunicati cum omnibus, qui eos docuerint scienter vel asseruerint a domino Stephano, parisiesi Episcopo, anno Domini MCCLXX die mercurii post festum beati Nicholai hyemalis. (Apud MANDONNET, 1908-1911, p. 111, nota 1, tradução nossa).
} 
Quem lhe forneceu elmo, couraça e malha teóricos para esta contenda foi seu mestre, Alberto Magno, mas não através do opúsculo De quindecim problematicus $^{5}$, redigido nesse mesmo período para responder a uma lista de quinze questôes apresentada pelo confrade Egídio de Lessines (treze das quais correspondiam exatamente às treze teses condenadas pelo bispo Estêvão Tempier) (NARDI, 1960, p. 133; RODRIGUES, 2015, p. 41). Com efeito, a resposta do dominicano de Bollstädt foi decepcionante, opinião confirmada também por Torrell: "Alberto responderá a essa consulta por seu De quindecim problematicus, mas é preciso dizer que o velho mestre de Colônia não é suficientemente convincente." (TORREL, 2008, p. 350).

A segunda proposição condenada por Tempier afirmava o seguinte: "Que esta é falsa ou imprópria: o homem entende (homo intelligit)." Esta fórmula era a demonstração e a expressão concreta da unidade humana: quem asseverava sua falsidade, atribuía à alma intelectiva (na qual se realizava o ato de entender, puramente espiritual) um ser separado do corpo. $\mathrm{O}$ arcebispo de Paris, portanto, condenando aqueles que declaravam ser falsa ou imprópria esta fórmula, visava reafirmar categoricamente a unidade do ser humano, composto de corpo e alma (sua forma substancial), excluindo toda possibilidade de introduzir a unicidade do intelecto possível separado para todos os seres humanos. A paternidade da expressão hic homo intelligit, no entanto, deve ser atribuída a Tomás que, de acordo com Masnovo, concentrou sua atenção nesta fórmula lapidar no combate contra o averroísmo: de fato, "ele recusa à alma intelectiva um ser separado do corpo, pois, caso contrário, não se poderia atribuir ao homem (ou seja, ao composto) o ato de entender, mesmo que este ato seja espiritual" (MASNOVO, 1932, p. 50, tradução nossa). O inspirador do Aquinate, no entanto, foi Alberto Magno com seu tratado De unitate intellectus, no qual reiterava que o princípio substancial vegetativo, sensitivo e intelectivo do homem era único. Como os dois primeiros se multiplicavam de acordo com os corpos, devia acontecer o mesmo com o terceiro: "Portanto, como o princípio vegetativo e o princípio sensitivo são enumerados segundo o número dos homens nos quais estão, também o princípio racional será enumerado segundo o número dos mesmos." ${ }^{\text {T }} \mathrm{O}$ dominicano alemão utilizou

\footnotetext{
${ }^{5}$ Há uma tradução em português deste opúsculo: ALBERTO MAGNO, S. Sobre o destino. Sobre os quinze problemas. Tradução de T. Tondinelli. Campinas, SP: CEDET, 2017.

${ }^{6}$ Quod ista est falsa vel impropria: Homo intelligit. (MANDONNET, 1908-1911 p. 111, tradução nossa).

7 Igitur cum vegetativum et sensitivum sint numerata ad numerum hominum, in quibus sunt, erit etiam rationale numeratum ad numerum eorundem. (ALBERTI MAGNI, 1975, p. 16, tradução nossa).
} 
este argumento contra aqueles que defendiam a unicidade do intelecto possível (ou, que é o mesmo, da alma intelectiva), afirmando que se multiplicava necessariamente conforme o número dos seres humanos. A argumentação posterior de Tomás através do axioma homo intelligit se fundamentava no princípio da alma como forma do corpo, após identificar (como fizera Alberto Magno) o princípio intelectivo com o princípio sensitivo: ambos concluíram "que a alma intelectiva era a forma substancial multiplicável com o corpo humano, enquanto princípio substancial de operação idêntico ao princípio substancial da operação sensitiva" (MASNOVO, 1932, p. 57, tradução nossa).

\section{O DE UNITATE INTELLECTUS: GÊNESE, ESTRUTURA E ANÁLISE}

A "disputa de Anagni”, conhecida com o título de Libellus de unitate intellectus contra averroístas, foi considerada por muitos o primeiro documento que testemunhava o começo do averroísmo. Deve-se frisar, entretanto, que não há um acordo entre os estudiosos acerca da existência real de um movimento averroísta: com efeito, o pensamento de Averróis exerceu, no século XIII, uma influência real e constante que ia muito além de um movimento determinado.

A redação do opúsculo deve ser colocada por volta de 1263-1264, já que o Bispo de Regensburg escreveu:

Com efeito, no livro Sobre a imortalidade da alma, demos provas suficientes, assim como no III livro do De anima e no II livro do De intellectu et intelligibili, onde, se alguém reparar sutilmente a força dos silogismos, acredito que náo terá nenhuma dúvida a respeito da separação da parte intelectiva. (ALBERTI MAGNI, 1975, p. 1, tradução nossa).

Junto com esses textos, a outra obra que o mestre dominicano citou diversas vezes no De unitate foi o comentário à Metafísica, (RODRIGUES, 2015, p. 41) concluído em 1263 ou 1264. O terminus ante quem é constituído pelo comentário ao Liber de causis (RODRIGUES, 2015, p. 41), redigido antes de 1271, que Alberto nunca mencionou no seu texto.

$\mathrm{O}$ argumento específico do tratado era a imortalidade pessoal da alma após a morte que os defensores da tese da unicidade do intelecto negavam. Como evidencia Rodolfi, (ALBERTO MAGNO, 2007, p. XXVI, tradução nossa) havia no centro do tratado as consequências negativas que esta tese tinha no plano moral e escatológico, relativas ao destino do homem e à 
possibilidade de uma imortalidade pessoal: admitindo a existência de um único intelecto para toda espécie humana, chegar-se-ia à negação da imortalidade do indivíduo e, portanto, da condição para os prêmios e os castigos eternos.

A divisão do texto é a seguinte:

- introdução;

- primeira parte: trinta objeçóes em favor da tese da unicidade do intelecto post mortem;

- segunda parte: trinta e seis argumentos em favor da tese contrária, ou seja, da imortalidade pessoal;

- terceira parte: solução de Alberto Magno, na qual ele expôs a própria posiçáo sobre o tema, seguida de uma resposta pormenorizada às trinta objeçóes apresentadas na primeira parte.

\subsection{INTRODUÇÃO}

$\mathrm{Na}$ introdução foram enunciados o argumento da discussão e a metodologia utilizada:

Junto àqueles que ensinam filosofia existe a dúvida se a alma é separada do corpo, e, se ela for separada, o que dela permanece e, concedendo ser o intelecto aquilo que permanece, qual a relação do intelecto que permanece após a separaçáo de uma alma com o intelecto que permanece após a separação de uma outra alma, se por ventura é o mesmo ou é diferente. É necessário apurar, por meio de razóes e silogismos, o que cumpre julgar e sustentar. Por isso, qualquer coisa que diga nossa religiáo, deixemo-la agora totalmente de lado, aceitando exclusivamente as verdades aceitas com a demonstração através do silogismo. (ALBERTI MAGNI, 1975, p. 1, tradução nossa).

Para o dominicano alemão, o objeto do debate não parecia ser uma heresia, mas uma dúvida (dubium est) que havia entre os professores de filosofia. Esta dúvida envolvia três questôes específicas:

1) a separação da alma após a morte;

2) aquilo que permanecia da alma após a morte e, caso fosse o intelecto,

3) se o intelecto que permanecia de uma alma fosse igual ou diferente ao intelecto que permanecia de outra alma. 
Quase no final da introdução, após delimitar o objeto do debate, Alberto concluiu:

\begin{abstract}
Esta, portanto, é a posição contra a qual devemos discutir; no entanto, ampliaremos a discussão examinando ainda em que pé está a coisa e procurando investigar se, deixando de existir estas duas posiçóes, aquilo que permanece de todas as almas seja algo idêntico ou diferente. (ALBERTI MAGNI, 1975, p. 1, tradução nossa).
\end{abstract}

Uma afirmação desse teor não era reveladora de uma atmosfera polêmica, como teria sido se o objeto em discussão tivesse envolvido uma doutrina ortodoxa; antes disso, parecia mais a tentativa de um mestre de resolver um problema especulativo de uma certa amplitude. Ao especificar a finalidade do debate, as próprias palavras de Alberto Magno comprovavam esta impressão: "Aceitando exclusivamente as verdades aceitas com a demonstração através do silogismo." (ALBERTI MAGNI, 1975, p. 1, tradução nossa). A própria metodologia escolhida pelo dominicano alemão, a fim de incrementar o interesse e a transparência da discussão, bem como sua solução exaustiva, revelava a ausência de uma discussão acalorada. Com efeito, na primeira parte do tratado, Alberto defendeu a posição de quem negava a imortalidade pessoal, apresentando argumentaçóes próprias ao lado daquelas oriundas de fontes filosóficas. A coerência metodológica do Doctor universalis foi meridianamente clara na sua opção de adotar uma aproximação exclusivamente filosófica à questão, a fim de demonstrar que a negação da imortalidade individual era inaceitável sob todos os pontos de vista, in primis filosófico.

Esta tese não foi identificada, no tratado, com um sistema filosófico particular: com efeito, o bispo de Regensburg se opôs a toda tradição peripatética, desde Alexandre de Afrodísia, Avicena, Averróis até Avempace. Entretanto, como sustenta Rodolfi, (ALBERTO MAGNO, 2007, p. XXVII, tradução nossa) é possível reconhecer as fontes de onde provinham os argumentos contra a imortalidade pessoal: onze foram derivados diretamente de autores não latinos (Abubacher: 6, 7, 24, 28, 30; Averróis: 4, 19, 27, 29; Hali: 24, 25, 30; Avicena: 1; Avempace: 25), enquanto os outros argumentos eram anônimos (embora representassem, com toda probabilidade, a própria contribuição de Alberto Magno): "Estes são os argumentos que coletamos, em parte do nosso próprio engenho, em parte das coisas que foram ditas pelos peripatéticos, que são muito difíceis de serem resolvidas." (ALBERTI MAGNI, 1975, p. 13, tradução nossa). 


\subsection{PRIMEIRA PARTE}

Os trinta argumentos favoráveis à tese da unicidade do intelecto correspondiam a quatro eixos temáticos (ALBERTO MAGNO, 2007, p. XXVIII-XXIX):

- o primeiro eixo era constituído por dois princípios aristotélicos: a) o caráter de separação e não mistura com a matéria atribuídos ao intelecto; b) o princípio de individuação, segundo o qual aquilo que era numerado estava dividido, enquanto o que era imaterial era indivisível e único; dezessete argumentos, com algumas variaçóes, podem ser reconduzidos a esse primeiro eixo: 1, 2, 3, 4, 5, 6, 7, 10, 11, 12, 16, $22,23,24,25,28$ e 29;

- o segundo eixo era relativo à universalidade do conceito: a espécie inteligível abstraída da imagem sensível só podia permanecer universal se fosse recebida por um intelecto também universal (e, se o intelecto era universal, era também único para todos os homens); seis argumentos se fundamentavam nesse argumento: 8, 13, 17, 19, 20 e 27;

- o terceiro eixo se baseava na analogia entre o intelecto e a luz do sol que, sem deixar de ser única, espalhava-se sobre todos os corpos; três argumentos seguiam este raciocínio: 14, 15 e 16;

- o quarto e último eixo, sobre o qual se fundamentava o argumento 21 , era relativo à semelhança que devia haver entre o intelecto e a causa primeira, da qual recebia diretamente a luz inteligível:

O agente universal opera e sua intenção é que, aquilo em que opera, chegue a uma semelhança com ele na forma última. Logo, entre todas as formas, é a mais semelhante ao primeiro eficiente. Ora, esta forma última, é aquela que se acrescenta a todas as outras formas no gênero. Mas esta não é senão o intelecto, pois ela se acrescenta ao ser, ao viver, ao perceber e universalmente ao conhecer, com uma cognição distinta. Portanto este intelecto, entre todas as formas, é aquela que mais se assemelha ao agente primeiro e mais participa de seus bens nobres. Ora, náo cabe participar das riquezas daquilo que é nobre em modo particular, mas em modo universal, nem cabe participar pelo movimento, mas pela imobilidade, porque aquilo que participa particularmente, não participa das riquezas, e aquilo que participa pelo movimento, participa com indigência. Por conseguinte, o intelecto será uma certa natureza que não participa em modo particular, nem pelo movimento, e tal natureza nem é particular, nem distante da primeira fonte das riquezas. Portanto, o intelecto não é uma natureza particular nem distante, mas antes uma única inteligência conjunta por si 
mesma à causa primeira e que, a partir daquelas riquezas, irradia sobre as almas que participam da sua luz; se for assim uma, indivisível e imóvel em todas as coisas que participam da sua luz, segue-se necessariamente que, após a eliminação de todas as coisas, aquilo que permanece só pode ser o mesmo e único. (ALBERTI MAGNI, 1975, p. 10, tradução nossa).

\subsection{SEGUNDA PARTE}

$\mathrm{Na}$ segunda parte do tratado, Alberto Magno lançou mão de uma estratégia para estruturar os 36 argumentos contrários à tese da unicidade do intelecto: como o primeiro eixo dos argumentos favoráveis a essa tese se baseava no fato de o intelecto, separado do corpo, não possuir a matéria (causa da divisibilidade e da multiplicidade), o dominicano alemão quis mostrar que o intelecto, mesmo não possuindo um órgão corpóreo, pertencia ao ser humano enquanto faculdade que fluía da sua alma (ALBERTO MAGNO, 2007, p. XXIX, tradução nossa).

A reductio ad absurdum foi um argumento utilizado várias vezes pelo Doctor Universalis para expor as consequências inaceitáveis da tese da unicidade do intelecto, às vezes em relação à doutrina aristotélica, mas também a partir de hipóteses ad hoc, como, por exemplo, o argumento número 30:

O trigésimo argumento é que se, como estes dizem, o intelecto só se unir à alma pelo seu ato segundo através das formas da imaginação, segue-se que a alma do homem nada opera pelo intelecto, porque a luz do intelecto agente que brilha sobre as formas da imaginação, abstrai-as, torna-as universais e póe tais formas universais não na alma do homem, mas no intelecto possível, que é totalmente separado do homem. Portanto, também as próprias formas universais são separadas do homem. Então, nem o intelecto e nem o que é inteligível está unido ao homem. Mas o homem nada opera por aquilo que não for unido a ele. Portanto, o homem nada opera pelo intelecto; esta afirmação é tão desprezível que todo homem não deve prestar ouvido a ela, porque, então, ninguém cuidaria do próprio intelecto, a filosofia nada seria e tampouco a virtude intelectual. (ALBERTI MAGNI, 1975, p. 20, tradução nossa).

Os argumentos da segunda parte podem ser divididos em seis grupos (ALBERTO MAGNO, 2007, p. XXX):

1) metafísicos (de 1 a 8): “Todos estes argumentos são metafísicos e, sem dúvida, demonstrativos, todos fundamentados no ato e no efeito da causa formal que é um dos elementos que organizam o composto." 
(ALBERTI MAGNI, 1975, p. 15, tradução nossa); seu alicerce era o postulado da identidade entre o homem e o intelecto;

2) elementos da psicologia aristotélica $(9,10,11,12,13,18$ e 25), entre os quais a doutrina da consecutio animarum, com a qual o Filósofo explicou a relaçáo que havia entre as faculdades da alma entendida como um todo dinâmico e unitário;

3) doutrina aristotélica da origem da alma intelectiva (14, 15, 19, 21 e 24);

4) concepção da alma como motor do corpo (22, 23 e 29);

5) noçôes metafísicas de ato, potência, ato primeiro e segundo (26, 27 e 28);

6) doutrina da continuatio ou copulatio intellecti (30-36), utilizada por Averróis para explicar o conhecimento humano (segundo esta doutrina, o intelecto possível - concebido como substância separada - unia-se ao homem através das imagens produzidas pela fantasia).

No final da segunda parte, Alberto Magno exortou os ouvintes a fornecer novos argumentos e a satisfazer de forma autônoma a própria curiosidade:

Se quiséssemos explorar todos os inconvenientes destes erros, a discussão estender-se-ia excessiva e prolixamente. Portanto, sejam suficientes estas coisas, pois, a partir delas, outras semelhantes podem ser coletadas por qualquer um que tenha um pouco de conhecimento, principalmente aquele que lê livros de filosofia que publicamos sobre as partes da alma e sobre a filosofia primeira. (ALBERTI MAGNI, 1975, p. 21, tradução nossa).

\subsection{TERCEIRA PARTE}

$\mathrm{Na}$ terceira parte do opúsculo havia a solutio da questão, na qual vinha à tona a opiniấo de Alberto Magno sobre o tema: "Para que este erro, portanto, seja oportunamente eliminado, expliquemos brevemente a natureza do intelecto e nossa opiniáo a respeito, pois as coisas que aqui dizemos, alhures comprovamos e transmitimos detalhadamente." (ALBERTI MAGNI, 1975, p. 21, tradução nossa).

O dominicano alemão, retomando implicitamente o que afirmara anteriormente, fundamentou-se na natureza ancípite ${ }^{8}$ da alma para afirmar

\footnotetext{
${ }^{8}$ Do latim anceps, composto por duas am(bi), de duas partes, e caput, cabeça. Portanto, propriamente, que tem duas cabeças (ou seja, no nosso caso, que tem uma natureza dupla).
} 
a multiplicidade do intelecto. Com efeito, a alma podia ser considerada a partir de dois pontos de vista: enquanto emanada da causa primeira ela era substância e possuía o intelecto agente; em si mesma, ao invés, possuía faculdades orgânicas. Tudo o que emanava de Deus recebia dele o ser (o ato), mas em relação a ele era apenas possibilidade: isso, para o Doctor Universalis, devia-se ao fato de a alma possuir um intelecto agente que recebeu diretamente de Deus, e um intelecto possível que pertencia à sua própria potência:

E como esta natureza intelectual é motor do corpo natural e, com isso, permanece estável pela causa primeira, é necessário que, enquanto é motor, fluam dela as potências da vida, pelas quais, de acordo com as operaçōes da vida, move a natureza do corpo; e, enquanto subsiste pela causa primeira, fluem dela as potências pelas quais depende da causa primeira, assim ela, única na substância, possui um duplo ser, como é manifesto pelas coisas que foram ditas antes. Como, porém, em nenhum modo é em potência por aquilo que depende da causa primeira, mas é ato puro, o intelecto que age universalmente está presente nela. E sendo que ela é em potência por si mesma, como as outras substâncias intelectuais, o intelecto possível está presente nela; com efeito, toda natureza intelectual considerada em si mesma não é senão em potência e, semelhantemente, todo causado em si não é senão em potência; mas, enquanto é da causa primeira, é em ato e recebe seu ser por necessidade. (ALBERTI MAGNI, 1975, p. 22, traduçáo nossa).

Este caráter potencial da alma em relação a Deus (ato primeiro e único ser necessário), constituía o fundamento da multiplicidade das almas, bem como da individualidade delas, sem que, com isso, a matéria estivesse implicada. Com isso, o mestre dominicano rebateu os argumentos da primeira parte (que negavam a multiplicidade do intelecto defendendo a matéria como único princípio de individuação). A alma individual, sustentou Alberto, era composta por um princípio determinante (intelecto agente) e por uma potência (intelecto possível): sua individuação ou multiplicidade não dependiam da matéria, mas da potência que todo ente criado possuía e pela qual se diferenciava do Criador:

Mas àquilo que objetam em segundo lugar, cumpre dizer que o intelecto de uma alma é distinto do intelecto de outra alma pelo número, e esta divisão é semelhante à divisão pela quantidade. Como isso aconteça, porém, pode ser entendido assim: sem dúvida, de fato, se alguém disser que o intelecto provém da matéria, náo poderá evitar todos aqueles inconvenientes que a objeção apresentada deduz, e muitos outros que podem ser facilmente deduzidos, pois não tem nenhum sentido atribuir ao intelecto a matéria $\mathrm{e}$ 
negar-lhe todas as propriedades da matéria. (ALBERTI MAGNI, 1975, p. 24, tradução nossa).

Depois de expor a própria opinião, o dominicano alemão respondeu aos argumentos favoráveis à unicidade do intelecto apresentados na primeira parte, considerando dois problemas: a individualização do intelecto (baseada na sua imaterialidade) e a incompatibilidade da sua natureza individual com a capacidade de conhecer o universal. Para o primeiro problema, Alberto retomou aquilo que já afirmara na solutio: a alma, por sua natureza, era composta de um intelecto agente e de um intelecto possível, que representavam sua natureza dúplice, orientada, por um lado, ao mundo do devir e, do outro, ao mundo da pura intelectualidade (ALBERTO MAGNO, 2007, p. XXXV). Quanto ao segundo problema, ele lançou mão de uma comparaçáo entre o sol e o intelecto agente:

Donde, como o sol é algo determinado no gênero dos corpos, enquanto sua potência, na medida em que é regiâo das coisas visíveis pela luz, não é algo determinado nem individuado, assim se deve dizer que o intelecto no gênero da substância é algo individuado, enquanto a potência da luz intelectual, na medida em que é região das espécies intelectuais, não é determinada e nem individuada. Nesse modo, um intelecto penetra outro com a luz, como um astro penetra outro com sua luz, e assim nada proíbe que um único universal esteja em muitos intelectos como em uma só região e um só lugar dos inteligíveis. (ALBERTI MAGNI, 1975, p. 25, tradução nossa).

O intelecto, mesmo sendo individual, tinha a possibilidade de conhecer o universal porque sua capacidade de abstrair as formas era infinita, e nesse sentido (i.e., em relação à sua potência) era possível afirmar que o intelecto era universal. Quanto ao conceito universal, havia um modo particular do seu conhecimento (quando quem o recebia era o sujeito), e outro universal (enquanto forma de todos os entes). Para Alberto Magno, a universalidade nada mais era do que um atributo lógico pois a ideia, como ato psicológico, era algo individual (ALBERTO MAGNO, 2007, p. XXXVII).

\section{Conclusáo: o legado de Alberto Magno}

O legado que o bispo de Regensburg deixou para a solução de problemas inerentes à natureza da alma humana tinha uma clara ascendência averroísta: 
a imaterialidade absoluta do intelecto, a impossibilidade de reduzir a unidade entre intelecto e inteligível às uniôes de tipo hilemórfico, a continuação entre intelecto possível e intelecto agente. A contestação da unicidade do intelecto possível, que ocasionou a redação do De unitate intellectus, constituiu o resultado corajoso de suas opçóes psicológicas e noéticas assumidas frente a uma exegese inaceitável de Averróis, mostrando sua incompatibilidade com a doutrina aristotélica. Os argumentos que Alberto Magno apresentou no seu opúsculo foram proporcionais ao seu objetivo, que não era a refutação da síntese averroísta e sim a defesa da imortalidade pessoal do ser humano, negada pela tese da unicidade do intelecto. Esta doutrina, com efeito, não era associada pelo dominicano alemão apenas a Averróis, mas se tratava de uma tese bastante propalada e defendida pelos filósofos árabes. Com efeito, ele escreveu: "Se, portanto, se tirasse esta alma e aquela, seria um só aquilo que permaneceria de todas. Este argumento supóe que o intelecto não seja uma parte da alma, que é aquilo que quase todos os árabes supóem, eles que foram os primeiros a cair nesse erro." (ALBERTI MAGNI, 1975, p. 8, tradução nossa).

O papel marginal de figura de Averróis neste tratado se explicava pela falta de uma aproximação exclusivamente gnoseológica ao problema do intelecto (prioritária, ao invés, para os averroístas), e pelo domínio de um interesse teológico (a doutrina da imortalidade pessoal da alma). Por esta razão era secundário, para Alberto Magno, apontar as incongruências e os absurdos filosóficos resultantes da tese da unicidade do intelecto (em prol da qual apenas três argumentos foram atribuídos a Averróis).

A perspectiva de Tomás de Aquino, no seu tratado homônimo, apresentou muitas afinidades linguísticas e conceituais com a obra do seu mestre, sobretudo do ponto de vista psicológico e noético. A medievalística das últimas décadas, entretanto, orientou-se a diferenciar estas duas perspectivas, bem como a realçar a inadequação de uma leitura que via no Doctor Angelicus o herdeiro natural do Doctor Universalis. De Libera, em particular, afirmou que, para ler Alberto, era necessário esquecer Tomás ("il faut oublier Thomas d'Aquin”); de fato, o dominicano alemão representou "a filosofia medieval no seu estado nascente, no instante preciso em que o ideal filosófico tomava uma forma senão independente, pelo menos autônoma, na encruzilhada de culturas e de práticas, de formas de vida e de tensôes, de facçóes e de escolas" (DE LIBERA, 2007, p. 27). Uma comparação entre os dois tratados poderia corroborar esta afirmação. 
O opusculus de Alberto, conforme foi evidenciado acima, parece que não foi escrito contra o filósofo de Córdoba e nem contra os assim chamados averroístas. Tomás de Aquino, ao contrário, foi muito claro quanto a isso:

De fato, já há algum tempo impregnou-se em muitos um erro, a respeito do intelecto, originado do que disse Averróis, que se esforça por asseverar que o intelecto, que Aristóteles chama de "possível” e ele próprio, com um nome inadequado, "material”, é certa substância separada do corpo, de acordo com o ser, e não se une a ele de modo nenhum como forma; mais ainda, que esse intelecto possível é um só para todos os homens, contra o que já escrevemos muito anteriormente. Mas como a petulância dos que estáo errados náo cessa de resistir à verdade, o que propomos como nossa intenção é escrever de novo, contra o mesmo erro, algo pelo que o citado erro seja manifestamente refutado. (TOMÁS DE AQUINO, 2016, p. 19).

O Aquinate, desde as primeiras páginas, expôs claramente seu método argumentativo: operar no plano estritamente filosófico e, mais ainda, filológico (ALBERTO MAGNO, 2007, p. XLII). Com efeito, o primeiro capítulo do De unitate de Tomás confutou, através de uma minuciosa exegese literal, a interpretação averroísta do De anima de Aristóteles realizada no Grande comentário (KLIK DE LIMA, 2016). Para fazer isso, o dominicano de Roccasecca dispunha da paráfrase do texto aristotélico redigida por Guilherme de Moerbeke por volta de 1267. Lançando mão de toda sua erudição e força argumentativa, o Doctor Angelicus mostrou, ponto por ponto, que a tese da unicidade do intelecto estava em contradiçáo com o pensamento aristotélico. Contudo, não havia dúvida de que o alvo da censura de Tomás era Síger de Brabante, "o único que, antes de 1270, escreveu algo que pode ser relacionado de modo preciso às críticas de Tomás” (TOMÁS DE AQUINO, 2016, p. 9).

O De unitate de Alberto Magno, ao invés, não era uma obra de filosofia que queria consertar um erro de interpretação, mas sim de teologia racional (ALBERTO MAGNO, 2007, p. XLIII): lançando mão da razão, o dominicano de Bollstädt quis defender uma verdade de fé, a tese da imortalidade pessoal da alma. Por isso, o método escolhido pelos dois dominicanos foi diferente: enquanto Tomás quis dar uma contraexposição do De anima aristotélico, Alberto Magno utilizou este e outros textos do Estagirita para extrair argumentos contra a unicidade do intelecto. Se, para o primeiro, o uso correto da argumentação filosófica foi o objeto da disputa, para o segundo ela foi apenas funcional para resolver um problema teológico. 
RASCHIETTI, M. The importance and legacy of Albertus Magnus in the controversy over the unity of the intellect. Trans/Form/Ação, Marília, v. 42, p. 75-92, 2019. Edição Especial.

\begin{abstract}
The purpose of this paper is to highlight the importance and the legacy of the Dominican Albertus Magnus in the controversy with the defenders of the possible unity of the intellect of all mankind. To this end, a brief presentation of his treatise De unitate intellectus, written in 1263, will be given. After a historical contextualization that presents the Bishop of Regensburg's position in relation to Averroism, it will be shown how he inspired one of his most brilliant students, Thomas Aquinas, with regard to this topic. Moreover, it is pointed out that, for the Doctor Universalis, Averroes' contribution proved indispensable: the latter was able to indicate the correct way in which the intellect should be considered "immaterial", although his conclusion that there was a possible single intellect for all mankind was unacceptable.
\end{abstract}

Keywords: Albertus Magnus. Intellect. Averroism. De anima.

\title{
REFERÊNCIAS
}

ALBERTI MAGNI, S. Operum Omnium. Tomus XVII, Pars I. De unitate intellectus. Germany: Monasterii Westafalorum in aedibus Aschendorff, 1975. Edidit: Alfonsus Hufnagel.

ALBERTO MAGNO. Tratado sobre a prudência. Introdução e tradução: M. Raschietti. São Paulo: Paulus, 2017.

ALBERTO MAGNO. L'unità dell'intelletto. Testo latino a fronte. Introduzione, traduzione, note e apparati di Anna Rodolfi. Milano: Bompiani, 2007.

ANZULEWICZ, H. Sobre el desarrollo y posición de la teoria del conocimiento intelectual en el sistema de Alberto Magno. AnáMnesis: Revista Semestral de Investigación Teológica, v. 21, n. 41, p. 74-90, 2011.

ARISTÓTELES. De anima. Apresentação, tradução e notas de Maria Cecília Gomes dos Reis. São Paulo: Editora 34, 2006.

BIANCHI, L. L'errore di Aristotele: la polemica contro l'eternità del mondo nel XIII secolo. Firenze: La Nuova Italia Ed., 1984.

DE LIBERA, A. Albert le Grand et la philosophie. Paris: Librarie Philosophique J. Vrin, 1990.

DE WULF, M. Histoire de la philosphie médiévale. Louvain-Paris: Librarie Philosophique J. Vrin, 1936. V. 2. 
KLIK DE LIMA, A. Individualidade e vis cognitiva no Grande Comentário ao De Anima de Averróis. PERI: Revista de Filosofia da UFSC, Florianópolis, v. 08, n. 02, p. 102118, 2016. Disponível em: <http://www.nexos.ufsc.br/index.php/peri/article/viewFile/ 1856/1090>. Acesso em: 20 fev. 2019.

LENZI, M. Alberto e Tommaso sullo statuto dell'anima umana. Archives d'Histoire Doctrinale et Littéraire du Moyen Âge, v. tome 74, n. 1, p. 27, 2007. Disponível em: $<$ https:/www.cairn.info/revue-archives-d-histoire-doctrinale-et-litteraire-du-moyen-age2007-1-page-27.htm>. Acesso em 20 fev. 2019.

MANDONNET, P. Siger de Brabant et l'averroüsme latin au XIIIme siècle. Louvain: Éd. Inst. Sup. de Phil, 1908-1911.

MASNOVO, A. Alberto Magno e la polemica Averroistica. Rivista di Filosofia NeoScolastica, v. 24, n. 2, p. 162-173, 1932.

NARDI, B. Studi di filosofia medievale. Roma: Edizioni di Storia e Letteratura, 1960.

PETAGINE, A. Aristotelismo difficile: L'intelletto umano nella prospettiva di Alberto Magno, Tommaso d'Aquino e Sigieri di Brabante. Milano: Vita e Pensiero, 2004.

RODRIGUES, D. L. O conceito de memória na obra filosófica de Alberto Magno e seu significado para a educação. 2015. Tese (Doutorado em Educação) - Centro de Ciências Humanas, Letras e Artes, Universidade Estadual De Maringá, Maringá. Disponível em: <http://www.ppe.uem.br/teses/2015\%20-\%20Divania.pdf>. Acesso em: 20 fev. 2019.

SALMAN, D. Albert Le Grand et l'averroïsme latin. Revue des Sciences Philosophiques et Théologiques, v. 24, n. 1, p. 38-64, 1935.

STURLESE, L. L'averroismo nella cultura filosofica tedesca medievale. In: NIEWÖHNER , F.; STURLESE , L. (org.). Averroismus im Mittelalter und in der Renaissance. Zürich: Spur, 1994. p. 114-131.

STURLESE, L. Storia della filosofia tedesca nel medioevo: Il secolo XIII. Firenze: L. S. Olschki, 1996.

TOMÁS DE AQUINO. A unidade do intelecto contra os averroistas. Tradução, introdução e notas: Carlos Arthur Ribeiro do Nascimento. São Paulo: Paulus, 2016.

TORREL, J. P. Iniciação a Tomás de Aquino. São Paulo: Loyola, 2008.

Recebido: 30/12/2019

Aceito: 30/12/2019 